\title{
Sinonasal Malignancies and Charged Particle Radiation Treatment: A Systematic Literature Review
}

\author{
Marco Cianchetti and Maurizio Amichetti \\ Agenzia Provinciale per la Protonterapia Trento (ATrep), Via Fratelli Perini, 181, 38122 Trento, Italy \\ Correspondence should be addressed to Marco Cianchetti, cianchetti@atrep.it
}

Received 8 November 2011; Accepted 21 March 2012

Academic Editor: Michael Moore

Copyright ( $) 2012$ M. Cianchetti and M. Amichetti. This is an open access article distributed under the Creative Commons Attribution License, which permits unrestricted use, distribution, and reproduction in any medium, provided the original work is properly cited.

\begin{abstract}
Background. Paranasal and nasal cavity malignancies are rare tumors that frequently present at advanced stages. Tumor extension and anatomic complexity pose a challenge for their treatment. Due to their peculiar physical and biological properties particle radiation therapy, i.e. protons and ions can have a role in their management. We performed a systematic literature review to gather clinical evidence about their use to treat sinonasal malignancies. Materials and Methods. We searched the browsers PubMed and Medline as well as specific journals and conference proceedings. Inclusion criteria were: at least 10 patients, English language, reporting outcome and/or toxicity data. Results. We found six studies with data on clinical outcome. Carbon and helium ions were each used in one study, protons in four. Toxicity was specifically described in five studies. One reported acute toxicity of carbon ions, one dealt with brain toxicity from both carbon ions and protons. Three papers reported on visual toxicity: one from carbon ions, one from protons and one from both. Specific data were extracted and compared with the most pertinent literature. Conclusion. Particle radiation therapy is in its early phase of development. Promising results achieved so far must be confirmed in further studies.
\end{abstract}

\section{Introduction}

Paranasal sinus and nasal cavity malignancies are rare with an incidence rate estimated to range from 0.3 to 3.5 per 100.000 per annum $[1,2]$. They account for $3 \%$ of head and neck carcinomas and about $0.5 \%$ of all malignant diseases [3]. Squamous cell carcinoma is the most common histology; however, adenocarcinoma, adenoid cystic carcinoma, and undifferentiated carcinoma are relatively common too [4]. Several other histotypes like malignant melanoma [5], sarcoma [6], neuroendocrine tumors, namely, esthesioneuroblastoma, sinonasal undifferentiated carcinoma, neuroendocrine carcinoma, and small cell undifferentiated carcinoma $[7,8]$ can occur but are uncommon. Different incidence rates and pathology distribution are observed in different geographical areas and they are thought to relate mainly to professional exposure $[1,2]$ such as among wood and furniture $[1,2,9]$ workers. Males are usually more frequently affected than females [1].

Sinonasal malignancies present frequently at advanced stages due to late symptom onset. This, combined with the complex regional anatomy and the presence of several organs at risk (OARs) such as brain and optic structures, poses a challenge for their best management. The mainstay of treatment is surgery [10]: traditionally a craniofacial approach [11-13] has been employed. In recent years, in order to achieve wider resection margins and or to spare significant side effects, craniotomy and endoscopic approaches or their combination have been tested with encouraging results [14$16]$.

Radiation therapy has been employed either as adjuvant treatment for high-risk cases or as definitive therapy for unresectable disease. No clear evidence exists for a routine use of chemotherapy, which is administered generally in a caseby-case scenario $[17,18]$. Despite the therapeutic efforts, results are not completely satisfactory, with overall survival rates at 5 years ranging from $50 \%$ to $67 \%[19,20]$ for combined treatment and from $15 \%$ to $38 \%$ when radiation therapy is given as the sole treatment $[10,21]$. Furthermore, side effects associated with the treatment can be significant $[22,23]$. The use of highly conformal techniques has 
demonstrated its feasibility even in advanced stages and has shown a significant reduction of side effects [24].

Particle radiation therapy, that is, protons and heavy ions, is a relatively new type of radiation therapy that could enhance the therapeutic ratio for sinonasal malignancies. Protons and heavy ions share the same characteristic dose distribution, the so-called Bragg Peak, that is the release of almost all their energy in a few millimeters at the end of their path (see Figure 1). This peak is narrow and not suitable to treat target volumes so it has to be opportunely spread out, the so-called SOBP-Spread Out-Bragg Peak, allowing thus the delivery of high doses sparing at the same time OARs. Comparative treatment planning studies have demonstrated the robustness of heavy particle generated plans and showed their advantages over photon plans [25]. Protons have a relative biologic effectiveness (RBE) that is slightly higher than photons according to some authors [26], its value being around 1.1, or exactly the same as photons according to others [27]. Anyhow, the International Commission on Radiation Units and Measurements (ICRU) in its 78 report issued in 2007 recommends using a value of 1.1 [28]. More complex is the situation for heavy charged particles since the RBE is not constant along their path, but increases with increasing depth, reaching the maximum at the peak region [29]. RBE is dependent indeed by the microdosimetric pattern of energy deposition that is, the Linear Energy Transfer (LET) that increases as they slow down [30]. The advantage of high LET radiations is that there is less variation in radiosensitivity during the cell cycle, less reduction of repair of radiation injury, and lower oxygen enhancement ratio [31]. From preparatory studies, an RBE value of 3 for carbon ion was found at the distal part of the SOPB [32]. In order of taking into account the different $\mathrm{RBE}$ of particle radiation therapy, their dose is expressed in Gy (RBE) that is the product of the physical dose in Gy multiplied for the specific RBE [30].

An altered fractionation regimen is any radiotherapy schedule that differs from the standard delivery of 1.8$2.0 \mathrm{~Gy}, 5$ days a week for an overall treatment time of about 6-7 weeks. They can be classified as hyperfractionated, accelerated, or hypofractionated with possible combinations as well. They all try to increase the therapeutic index that is, the ratio of the probability of tumor control to the probability of normal tissue toxicity. Published papers in the head and neck field have proved their effectiveness in comparison to standard fractionation [33, 34]. Particle radiation therapy has been delivered as well with altered fractionation schemes taking advantage of its particular physical and biological properties $[35,36]$. When comparing studies that employed different fractionation regimes, it is useful to refer to the Biologically Effective Dose (BED). This mathematical formula, $\mathrm{BED}=n d(1+d / \alpha / \beta)$, [37], allows comparison of the toxicity or efficacy of different fractionation regimes knowing the number of fractions $(n)$, the single dose $(d)$, and the $\alpha / \beta$ ratio that is a radiobiological parameter that characterizes the response of every tissue to radiations.

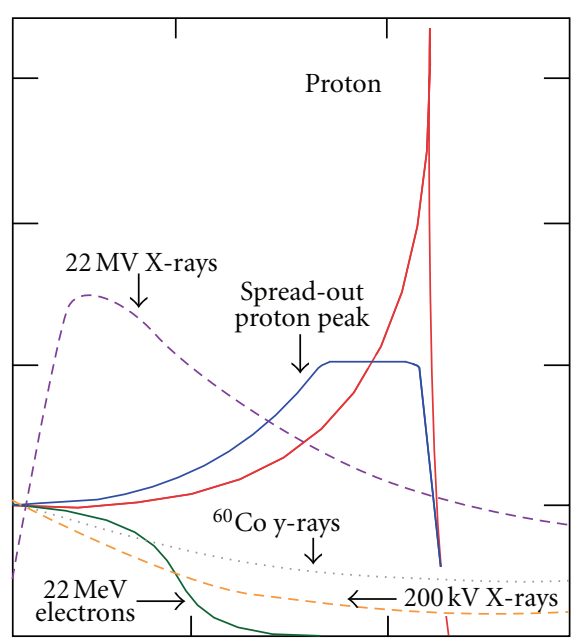

FIgure 1: Bragg peak and Spread-Out Bragg Peak (SOBP) for a proton beam in comparison with photon and electron dose distributions.

Since particle radiation therapy is not very widespread and basically still under development, data of its use to treat sinonasal malignancies are scant.

In this paper we performed a systematic review of the literature to gather all the clinical experience so far accumulated on this issue focusing on outcome and side effects.

\section{Materials and Methods}

ThePopulation-Interventions-Comparators-Outcomes (PICO) [38] framework was used to find appropriate keywords used to search the databases. Free text words and Mesh terms for paranasal sinus malignancies or particle radiation therapy or outcome or toxicity were generated and then combined according to Boolean operation "AND" or "OR." A research of the literature was carried out in PUBMED and MEDLINE first in August 2011 and then updated in October 2011. Manual search of the bibliography of pertinent papers was performed too. Any study known by any author was also considered for inclusion.

Eligibility criteria were as follows: studies published in the English language, reporting outcome and/or toxicity data on definitive treatment with particle radiation treatment of nasal and paranasal sinus malignancies. Studies were accepted if photon radiation therapy was combined with particle radiation and if radiation therapy was used either in definitive, adjuvant, or neoadjuvant setting. Any use of chemotherapy was allowed. Studies had to include at least 10 patients and to report data on tumor control and/or on toxicity. Studies including multiple head and neck sites were considered and included if it was possible to extract specific information on sinonasal malignancies. In case of publications with overlapping data, the study with the largest number and wider data was chosen. Review articles, case reports, and planning studies were not considered.

Data extracted from publications meeting the eligibility criteria were first author, year of publication, institution, 


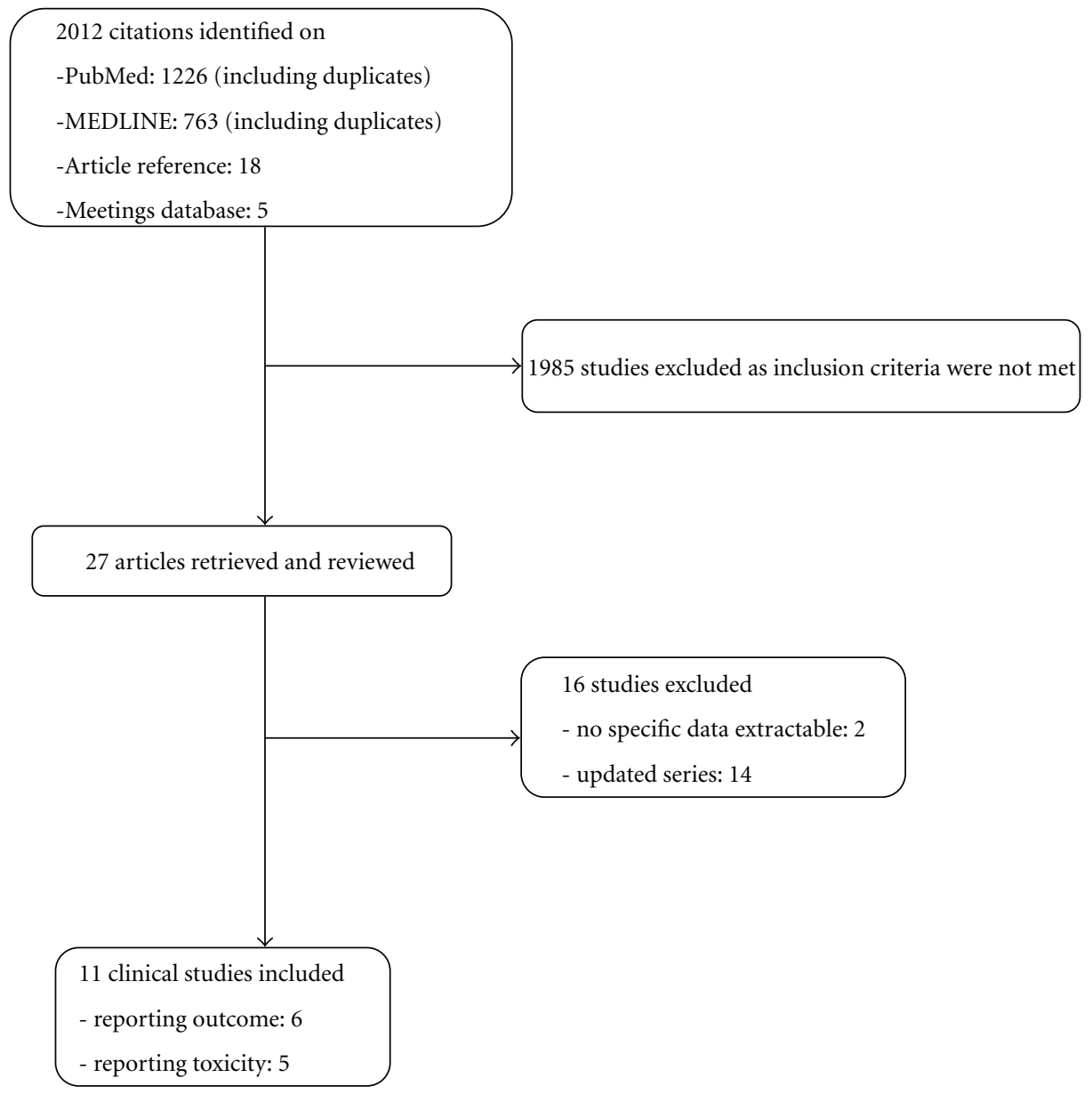

FIGURE 2: Flowchart of the searching process.

number of patients, gender, median age, pathology, stage, type of surgery received if any, type of chemotherapy received if any, and followup. Regarding radiation treatment, the following data were extracted: possible combination with photon, type of particle used, RBE employed, total dose, dose per fraction, number of fractions and number of fractions a week of the particle used, total dose, dose per fraction, number of fraction and number of fractions a week of photons; combined total dose was reported as well. For studies reporting results on tumor control the following data were recorded: local, regional and distant control, overall survival, type, scale and grade of toxicity, time to toxicity, and risk factors individuated. For studies dealing particularly with toxicity apart from the available data as above, the diagnostic criteria used were reported as well as the maximum dose to affected organs and side effect risk factors. Any toxicity scale used was also reported.

\section{Results}

The initial literature research identified 2012 studies including duplicates (see Figure 2). 1985 were excluded after reading the title or the abstract, as they did not fulfill the inclusion criteria. Twenty-seven studies remained and were considered for inclusion. After thorough reading of the full text, two studies were excluded as specific data of sinonasal malignancies were not available and fourteen were also excluded as they have subsequently been updated or because their data had already been included in other papers with larger numbers. At the end of the searching process, we identified six studies reporting outcome data (see Tables 1, 2, 3) of which two dealt with ions and four with protons. Five studies reporting exclusively toxicity were also included, two on ions, one on protons, and two on both (see Tables 4, 5).

3.1. Studies Reporting Outcome Data. All the studies reporting data on outcome have been published in peer-reviewed journals apart from the one from Malayapa [39] that has been presented at the 52nd annual meeting of the American Society for Radiation Oncology and published in the relative proceedings.

The first publication included in the paper, by Castro et al. [40], dates back to 1994 and reports results from "The University of California-Lawrence Berkeley Laboratory." Even though the paper deals with skull base malignancies, specific data on 22 paranasal and nasal cavity malignancies 


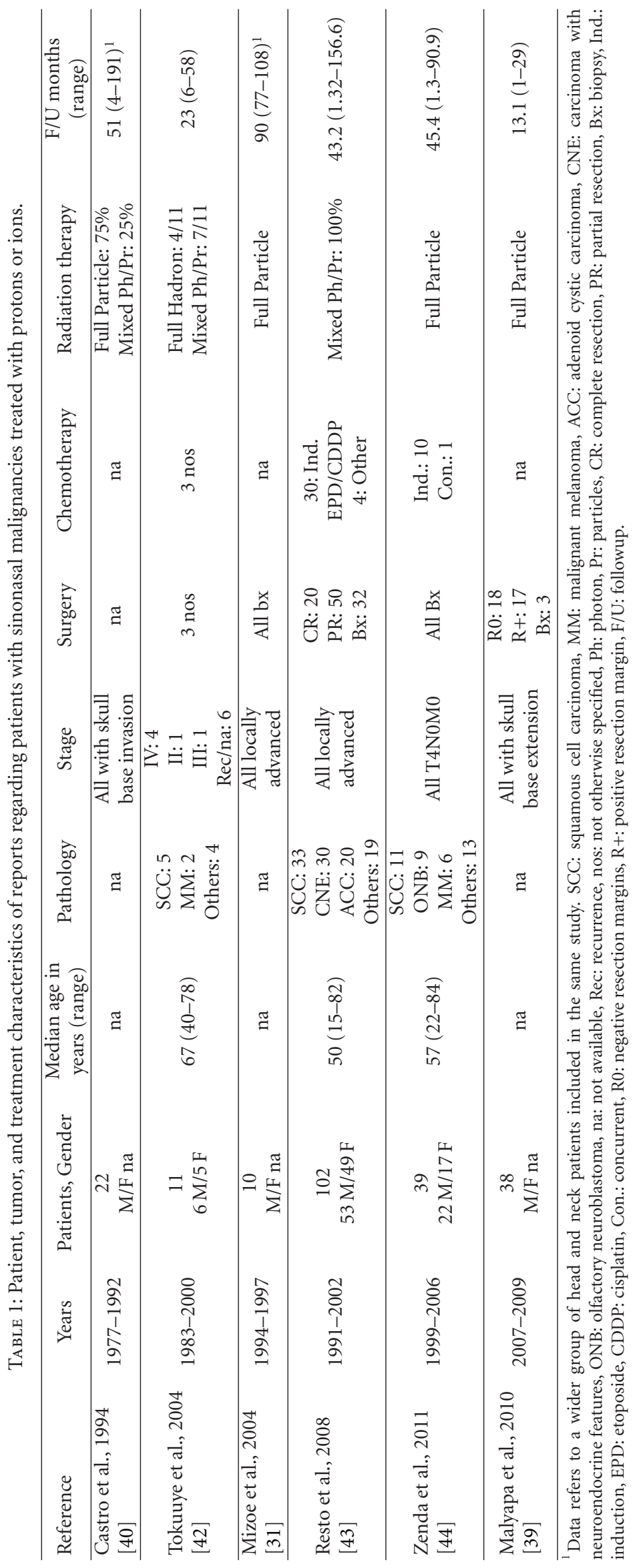




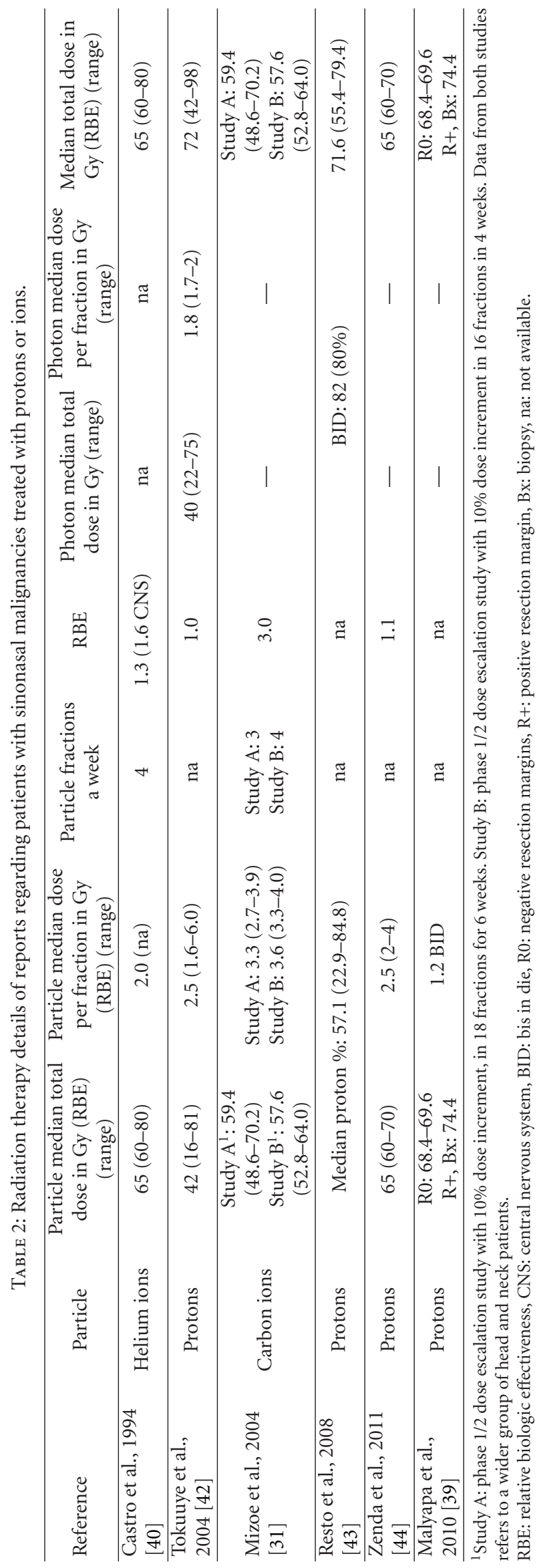




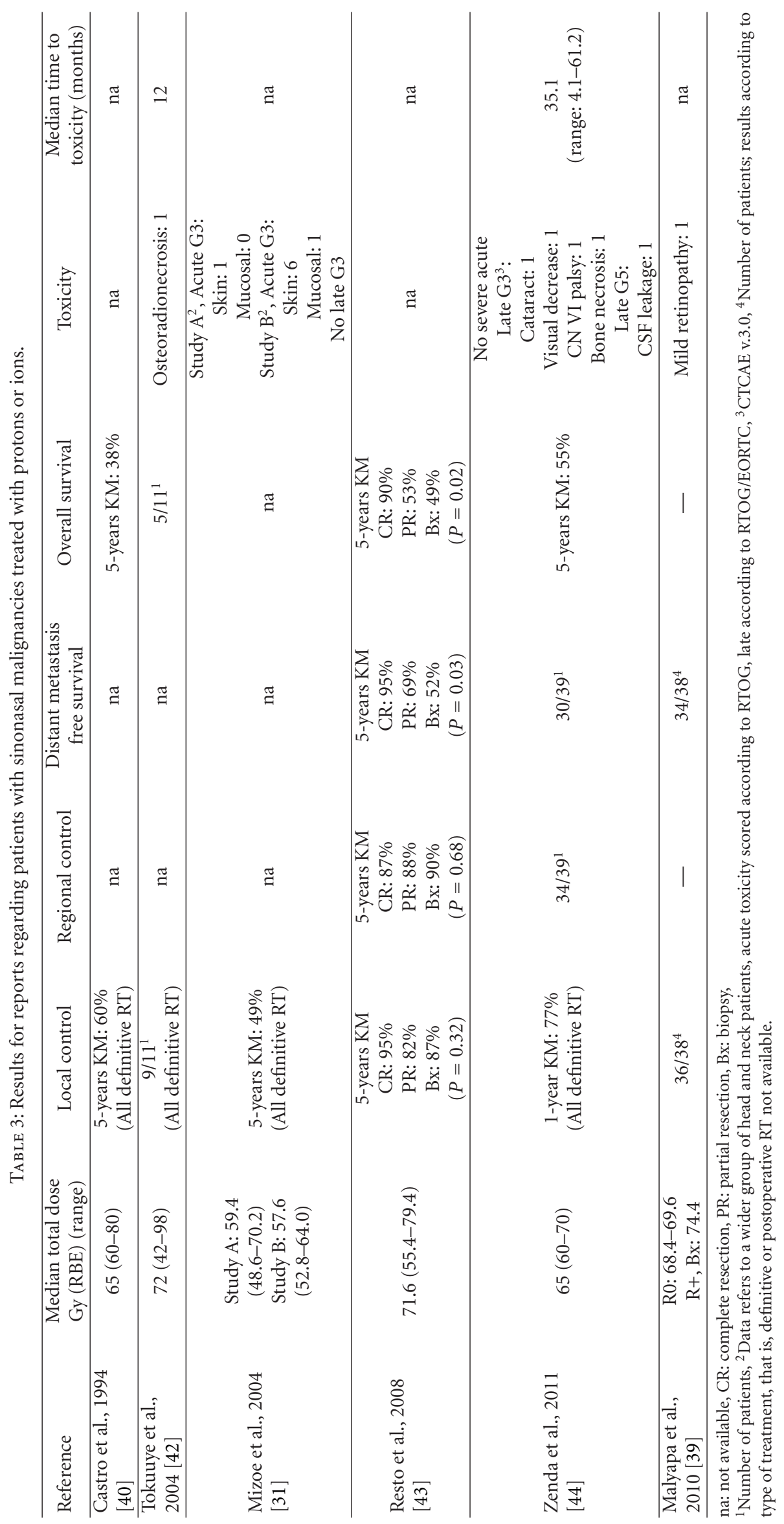




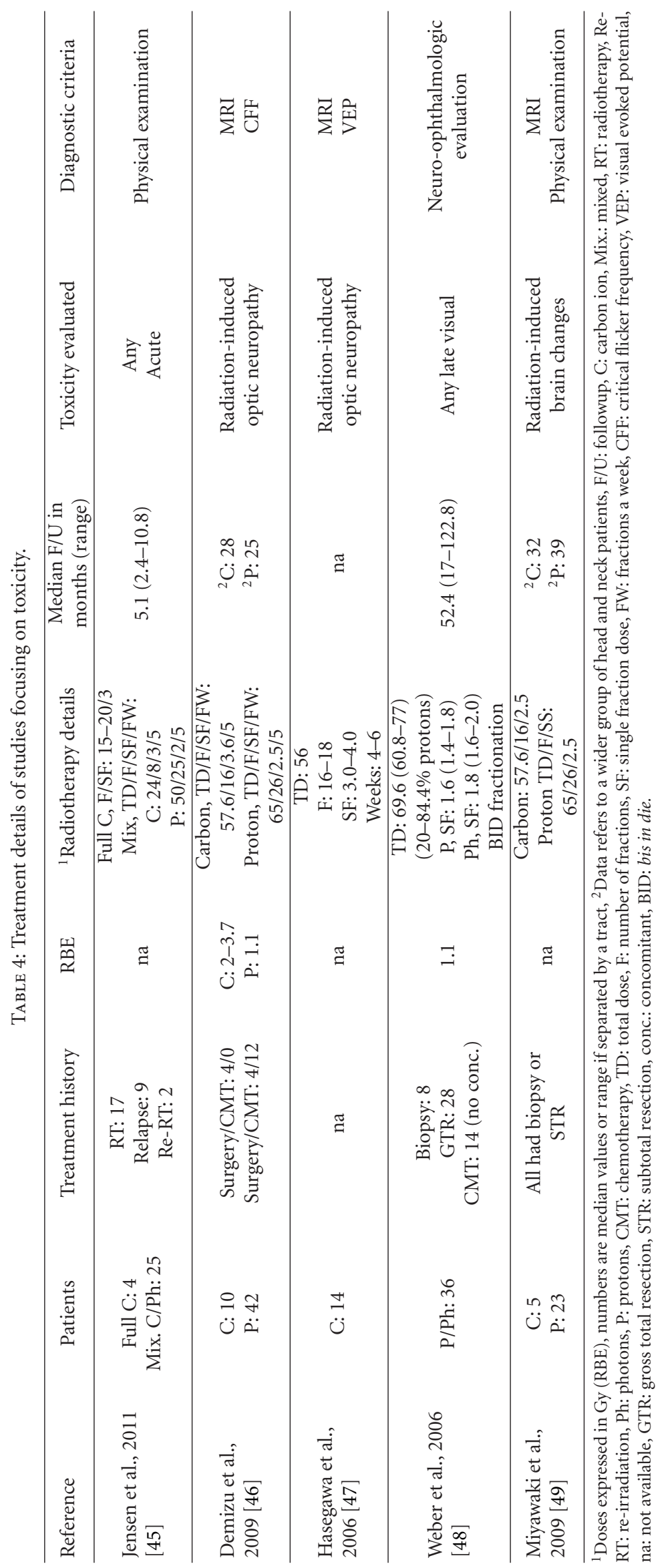




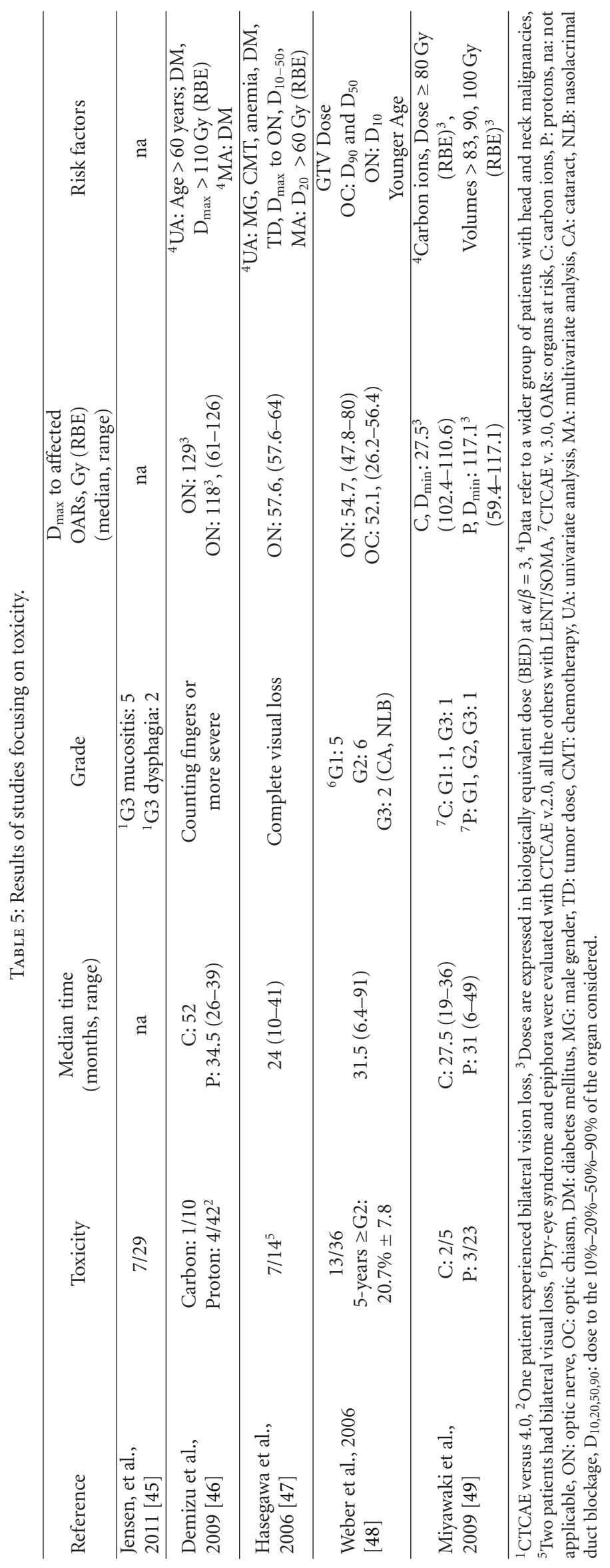


were available. All the patients received combined photon and helium ions radiotherapy for their tumor extending to the cranial base. Energies used in the synchrocyclotron were $215 / 232 \mathrm{MeV} / \mathrm{u}$; RBE was 1.3 except for central nervous system where it was considered to be 1.6. Total dose ranged from 60 to $80 \mathrm{~Gy}$ (RBE), median $65 \mathrm{~Gy}$ (RBE). Further details on general treatment were not reported. Five-year actuarial local control and overall survival were $60 \%$ and $38 \%$, respectively. Data on toxicity are difficult to extract since they refer to a wider group of patients with other malignancies and treated also with neon ions. It would seem anyhow that the largest amount of toxicity is related to the use of neon ions.

Mizoe et al. [31] published the results from the NIRS (National Institute of Radiological Sciences), Heavy Ion Medical Accelerator in Chiba, Japan. Since 1994, they have been using carbon ions because of their biologic and physical characteristics. Carbon ions' LET and RBE increase with depth reaching the maximum at the Bragg Peak: here they show an RBE of 3.0 if compared to photons [41]. Furthermore, experiments have demonstrated that increasing the carbon ion dose fraction tends to lower the RBE both for tumor and normal tissues, but more pronouncedly for the latter [35]. Hypofractionation schemes can be, therefore, used in carbon ion radiotherapy to increase the therapeutic ratio. Mizoe et al. [31] report the results of two dose escalation clinical studies for patients with multiple head and neck sites. Patients were treated, respectively, according to a schedule based on 18 fractions in three fractions a week for six weeks (Group A) or to another based on 16 fractions for four weeks in four fractions a week (Group B). Doses for each group were escalated every three to five patients, in $10 \%$ increments starting from $48.6 \mathrm{~Gy}$ (RBE) for Group A and from 52.8 Gy (RBE) for Group B. Median total dose for Group A was 59.4 Gy (RBE) (range: 48.6-70.2 Gy (RBE)) and 57.6 Gy (RBE) (range: 52.8-64.0 Gy (RBE)) for group B. No photons were employed. Acute reactions were scored according to the RTOG toxicity criteria system, late to RTOG/EORTC. The Kaplan-Meier local control for both groups was $49 \%$ at five years. Toxicity was reported for the entire cohort and no specific data on sinonasal tumors were retrievable. Acute Grade (G) 3 skin toxicity was seen in one Group A patient and in six Group B patients; G3 mucous membrane toxicity just in one Group B patient. No greater than G3 toxicity was observed.

Tokuuye et al. [42] from the University of Tsukuba, Proton Medical Research Center (PMRC), Japan, reported data of eleven patients with sinonasal malignancies, treated with protons (four) or with a combination of photons and protons (seven). They all had inoperable disease or refused surgery. Median total dose delivered was $72 \mathrm{~Gy}$ (RBE) (range: 42-98 Gy (RBE)). RBE value was 1.1. Local control was achieved in nine out of eleven patients and at the moment of the analysis five out of eleven patients were alive. One case of osteoradionecrosis was observed. Again, no specific sinonasal toxicity data were distinguishable from that of other head and neck sites. In the toxicity analysis a trend for $\operatorname{BED}_{(\alpha / \beta=3)}>130 \mathrm{~Gy}(\mathrm{RBE})$ was associated with late toxicity as well as with high fraction size.
Data from Massachusetts General Hospital, Harvard Cyclotron Laboratory, Francis Burr Proton Center, USA, are available in the paper of Resto et al. [43] From 1991 to 2002, 102 patients with locally advanced sinonasal malignancies of various histology received a mixed photon/proton treatment. Radiotherapy was given as definitive treatment in 32 cases, as adjuvant after partial resection in 50, and as adjuvant after complete resection in 20. Median total dose was $71.6 \mathrm{~Gy}$ (RBE); median percentage of protons was $57.1 \%$. Twice-aday fractionation schemes were employed in $80 \%$ of the cases. Local control was $95 \%, 82 \%$, and $87 \%$, respectively, for patients with complete resection, partial resection, and biopsy only. Analogously overall survival was $90 \%, 53 \%$, and $49 \%$, respectively. Regional control and distant metastasisfree survival were, respectively, $88 \%$ and $69 \%$.

Zenda et al. [44] from the National Cancer Center Hospital East, Chiba Japan, reviewed their results for 39 patients treated with proton radiation therapy. They all had T4N0M0 unresectable disease of various pathologic types. A full course of proton therapy, RBE 1.1, was delivered to a median total dose of $65 \mathrm{~Gy}$ (RBE) with a median dose per fraction of $2.5 \mathrm{~Gy}$ (RBE). Actuarial one-year local control and five-year overall survival were $77.0 \%$ and $55 \%$, respectively. Severe acute toxicity was not observed. Late toxicity G3-5 was reported in 5 patients $(12.8 \%)$, G5 in 1 patient $(2.6 \%)$ who suffered a CSF leakage.

The University Of Florida Proton Therapy (UFPT) Institute's experience is reported in the paper of Malyapa et al. [39] since January 2007, they have treated 38 patients with various histotypes of sinonasal malignancies of which three were in the definitive setting and 35 in the adjuvant setting. Positive margins were present in 17 cases of the latter. Maximum total doses for patients with negative margins ranged between 68.8 and $69.9 \mathrm{~Gy}$ (RBE), maximum dose for patients with positive margins or unresectable disease was 74.4 Gy (RBE). In every case, a twice-a-day fractionation regime was employed: single dose was $1.2 \mathrm{~Gy}$ (RBE) with fractions separated each other at least by six hours. At the moment of the analysis, two in-field progressions, one meningeal seeding, and three distant metastases were observed. One case of retinopathy within the treated volume occurred without significantly impairing acuity vision.

3.2. Studies Reporting Toxicity Data. A total of five studies dealing specifically with toxicity after particle radiation therapy were found. Jensen et al. [45] from the University of Heidelberg, documented exclusively acute toxicity for 29 patients with T4 sinonasal malignancy treated with carbon ion plus or minus photon radiotherapy to a median dose of 73 Gy (RBE). Accrual period was from November 2009 to August 2010 during which 17 patients received definitive treatment, two reirradiations, and nine radiotherapy after local relapse. Carbon ion total dose was $24 \mathrm{~Gy}$ (RBE) delivered in fractions of $3 \mathrm{~Gy}$ (RBE); IMRT total dose was $50 \mathrm{~Gy}$ in 25 fractions. Acute toxicity was scored according to CTCAE versus 4.0. There were no G4 or G5 toxicities and toxicity related interruption. Mucositis and dysphagia G3 occurred five and two times, respectively. 
Demizu et al. [46], from the Hyogo Ion Beam Medical Center, Japan, described side effects for 104 patients treated with carbon ions or protons for their tumor adjacent to optic nerves. Nasal cavity or paranasal sinuses were involved in 52 cases of which $10(19.2 \%)$ received carbon ions and 42 $(80.8 \%)$ proton therapy. Carbon ion total dose was $57.6 \mathrm{~Gy}$ (RBE) in 16 fractions; proton total dose was $65 \mathrm{~Gy}(\mathrm{RBE})$ in 18 fractions. Both treatments were administrated five days a week. Visual loss resulting from optic neuropathy was seen at 52 months in one (10\%) patient who had received carbon ions and at a median of 34.5 months in four patients $(9.5 \%)$ that had received protons. At univariate analysis age $>60$ years, diabetes mellitus and $\mathrm{BED}_{\max }>110 \mathrm{~Gy}(\mathrm{RBE})$ $(\alpha / \beta=3)$ were observed as possible risk factors. Diabetes was statistically significant at multivariate analysis too.

In the paper of Hasegawa et al. [47], from the National Institute of Radiological Sciences (NIRS) in Chiba, Japan, 14 patients with paranasal or nasal malignancies that received proton radiation treatment are included. It was not possible to retrieve details on other treatments received since they are described with those of patients with other head and neck malignancies. Significant visual loss was reported in seven patients $(50 \%)$, for whom optic nerve sparing had been difficult due to tumor involvement. Risk factors for the entire group at univariate analysis were male gender, chemotherapy, anemia, diabetes mellitus, prescribed tumor dose, $\mathrm{D}_{\max }$ of the optic nerve $>57 \mathrm{~Gy}(\mathrm{RBE})$, and $\mathrm{D}_{10-50}$. At multivariate analysis, $\mathrm{D}_{20}>60 \mathrm{~Gy}$ (RBE) was still significant.

Weber et al. [48] described the visual outcome for patients treated with accelerated combined proton-photon radiotherapy for advanced sinonasal malignancies at Massachusetts General Hospital, Harvard Cyclotron Laboratory, Francis Burr Proton Center from 1991 to 2001. Given the demonstrated higher efficacy of altered fractionation regimens towards head and neck malignancies [33], a median dose of $69.6 \mathrm{~Gy}(\mathrm{RBE})$ was given to 36 patients twice a day, with a median fraction size of $1.8 \mathrm{~Gy}(\mathrm{RBE})$ for protons and $1.6 \mathrm{~Gy}$ for photons. Percentage of cases treated with protons ranged between $20 \%$ and $84.4 \%$. Complications of the optic nerves, retina, and lenses were scored according to CTCAE versus 2.0 scale, of all the others visual organs to LENT. Grade 3 late toxicity occurred in 2 patients (8.3\%), G2 in $6(16.7 \%)$ and G1 in $5(13.9 \%)$. No retinopathy or optic nerve damage higher than G1 was observed. The reported 5 -year probability of higher than G2 toxicity was $20.7 \% \pm$ $7.8 \%$. Risk factors were GTV dose, age, D50 and D90 to the optic chiasm, and D10 and D50 to the optic nerve. No association was found between tumor localization in respect to the optical apparatus and toxicity.

The experience of The Hyogo Ion Beam Medical Center about radiation-induced brain injury after proton or carbon ions is reported in the paper of Miyawaki et al. [49]. Twentyeight patients with sinonasal malignancies, out of fifty-nine of the whole group with head and neck cancers, received particle radiation therapy either as carbon ions, five, or protons, twenty-three. The total dose for the former group was $57.6 \mathrm{~Gy}(\mathrm{RBE})$ in 16 fractions of $3.6 \mathrm{~Gy}(\mathrm{RBE})$, for the latter was $65 \mathrm{~Gy}(\mathrm{RBE})$ in 26 fractions of $2.5 \mathrm{~Gy}$ (RBE). To compare different fractionation schedules they used a biologically effective dose with $\alpha / \beta$ value of 3.6. Radiationinduced brain changes (RIBCs) were evaluated by MRI findings on T2-weighted or postcontrast images and graded according to the LENT-SOMA scale. Related symptoms were scored according to CTCAE versus 3.0 scale. After a median interval of 31 (range: 6-49) and 27.5 (range: 1936) months, respectively, three patients, treated by protons, and two by carbon ions developed radiation-induced brain changes. Radiologic toxicity grades for the three protonstreated patients were G1, G2, and G3 and for the two carbon ions-treated patients were G3 and G2. For protons-treated patients, clinical grading was G1 for one and G2 for two, meanwhile it was G3 and G1 for the two carbon ionstreated patients. G3 clinical toxicity consisted of epilepsy requiring steroids and anticonvulsants. From the analysis of the whole group, carbon ions were statistically more frequently associated with RIBCs than protons $(P=0.02)$. Minimal median dose to RIBCs sites for the three proton patients was $117.1 \mathrm{~Gy}(\mathrm{RBE})_{3}$ (range: 59.4-117.1 Gy (RBE)) and $27.5 \mathrm{~Gy}(\mathrm{RBE})_{3}$ (range: 102.4-110.6 Gy $(\mathrm{RBE})_{3}$ ) for the two receiving carbon ions. Most of the RIBCs were induced by doses $\geq 80 \mathrm{~Gy}(\mathrm{RBE})_{3}$, occurring within two years from radiation in comparison to those induced by lower doses that developed after two years. Lobe volumes receiving more than 83, 90, and $100 \mathrm{~Gy}(\mathrm{RBE})_{3}$ were significantly associated with RIBCs.

\section{Discussion}

We were able to find 11 studies reporting outcome and/or toxicity results relative to the use of particle radiation therapy for the treatment of paranasal sinus and nasal cavity malignancies. There are some common limitations for these studies that must be emphasized. All but one study (Mizoe et al. [31]) were retrospective. Six of them reported data on multiple head and neck sites, and it was necessary to extract specific numbers for sinonasal malignancies. Moreover, they included few patients accrued over a long period of time. Some studies have a short followup period. Not all the treatments were delivered in dedicated facilities so that logistic hurdles had to be overcome in this case $[40,42]$. Frequently, various pathologic types are grouped together even if it is well known that response to treatment varies among them $[4,20]$. Lastly, it was not always possible to retrieve all the details regarding patients' general management. Nonetheless, some conclusions from the available data can be made.

Heavy particle radiotherapy is in its early phase of development, and it is mainly employed for unresectable or high-risk cases. This type of radiation therapy combined with photons or not is feasible and well tolerated by patients either as definitive or as adjuvant treatment. The delivery of the prescribed dose was possible in all studies, and all patients could complete their treatment. Altered fractionation schemes were safely employed to increase the therapeutic ratio $[31,39,44,48]$, but other studies $[42,49]$ found that late radiation toxicity can be related to the high single fraction dose. 
Local control rates compare positively with those from Institutions that used photon radiation therapy (Table 6). Local control rates at 5 years achieved with conformal photon radiotherapy are around $62 \%-84 \%[20,52]$ for the postoperative setting and around $21 \%-43 \%[10,21]$ for definitive treatment. Resto et al. [43] showed local control rates at 5 years according to extent of resection that were $95 \%, 82 \%$, and $87 \%$ for complete resection, partial resection, and biopsy only, respectively. At univariate analysis, these figures did not differ significantly $(P=0.32)$. Castro et al. [40] reported a 5 year local control rate of $60 \%$; Zenda et al. [44] had one-year local control of $77 \%$, for 39 patients with locally advanced disease. Malyapa et al. [39] at the moment of the analysis reported that 36 out of 38 patients were free of local disease; for Tokuuye et al. [42], 9 out of 11 patients were free of local recurrence. The apparently lower local control rate from Mizoe et al. [31] must be taken into account cautiously considering that it was a Phase I/II study whose main purpose was to determine the normal tissue tolerance dose. Indeed some of the patients were given a dose that was thought to be $80 \%$ of the radical dose needed for advanced head and neck cancers. Interestingly, in the study of Resto et al. [43] local control was found to be independent from the extent of resection. Rates of distant metastasis freesurvival and overall survival were significantly different in case of complete resection, $95 \%$ and $90 \%$, respectively, versus partial, $69 \%$ and $53 \%$, respectively, or biopsy only, $52 \%$ and $49 \%$, respectively $(P=0.03, P=0.02)$.

In general, for particle radiation therapy studies, rates of distant metastasis free-survival and overall survival are not substantially different from other studies. Obviously, this means that an efficient systemic therapy capable of dealing with metastasis is needed for particle therapy too.

Regional control is reported in the papers of Resto et al. [43] and Zenda et al. [44] only. Details of neck treatment are not reported extensively; regional control rates are similar being $88 \%$ and $87.2 \%$, respectively, confirming that regional failures are quite infrequent in this disease.

Acute toxicity seems to be mild, well tolerated, and does not interfere with treatment delivery as pointed out in the specific paper by Jensen et al. [45]. Late toxicity was not reported extensively by all studies of the group reporting data on outcome. Mizoe et al. [31] reported no late toxicity; Tokuuye et al. [42] reported just one case of osteoradionecrosis. The only G5 toxicity was described by Zenda et al. [44], which was due to CSF leakage. Late toxicity was specifically reviewed in four papers, three of them dealing with visual side effects and one with CNS side effects. Median time to the onset of visual side effects ranged between 24 and 52 months. In the study of Weber et al. [48], higher doses were associated with faster development of side effects, analogously to what already described by other authors [53]. Radiation-induced optic neuropathy leading to severe visual loss occurred in five out of fiftytwo $(9.6 \%)$ and in seven out of fourteen $(50 \%)$ patients for the studies of Demizu et al. [46] and Hasegawa et al. [47], respectively. The latter figure may seem high, but it is to note that all the optic nerves showing high-grade toxicity had been invaded by the tumor making it almost impossible to spare them. The negative effect of the high RBE of carbon ions cannot be completely ruled out though. The result by Demizu et al. [46] seems acceptable considering the particular location of disease and when compared to other data. Jiang et al. [54] reported blindness due to optic neuropathy in 8 out of $98(8.1 \%)$ evaluable patients who had received radiation therapy for sinonasal malignancies. In a previous publication from Massachusetts General Hospital, Habrand et al. [55] reported data on neurovisual outcome after proton radiotherapy for upper clivus malignancies; two patients out of fifteen (13.3\%) developed visual deterioration at 10 and 36 months, respectively. This was due to optic nerve and optic chiasm damage in one and to bilateral optic nerve damage in the other. Results from the study of Weber et al. [48] are encouraging, being that any type of visual toxicity $\geq \mathrm{G} 2$ is around $20 \%$. In fact, they only had two G3 complications out of thirty-six patients (8.3\%), namely, a cataract and a nasolacrimal duct blockage. Jiang et al. [54] described a total of 60 ipsilateral visual events in 178 patients treated (33.8\%); seven of them experienced also contralateral visual impairment.

Among the possible risk factors, all the studies of particle radiation therapy found important the maximum dose delivered. This confirms both the concept that many optic structures are serial organs and the results from previous studies. Parsons et al. [22] observed indeed no injuries in 131 patients with head and neck malignancies if their optic nerves were irradiated to less than 59 Gy. Jiang et al. [54] in their study about 219 individuals with cancers of the nasal cavity and paranasal sinuses found that the radiation dose was the predominant determinant for optic nerves and optic chiasm injury with no patient receiving less than 50 Gy showing any impairment. Analogously, Takeda et al. [56] did not observe any retinal complications for patients receiving less than $50 \mathrm{~Gy}$. Habrand et al. [55] suggested a threshold value of $55 \mathrm{~Gy}$ (RBE) associated with a $10 \%$ major complication rate. Urie et al. [57] found as well that the dose is a significant predictor of cranial nerve injury but with a value of $70 \mathrm{~Gy}$ (RBE) that is higher than what is commonly reported.

A volume factor for the irradiated OAR has been individuated as risk factor in the study of Hasegawa et al. [47]. The dose to the $20 \%$ of the optic nerve higher than 60 Gy (RBE) was significantly associated with visual loss at multivariate analysis. This is in accordance with the findings of Weber et al. [48] that reported partial OAR volume irradiation as a risk factor even if they pointed out that setup uncertainties and contouring variability may confound data. Takeda et al. [56] found as well that irradiated retina area correlates with the incidence of sever late complication.

Dry-eye syndrome is a serious side effect associated with head and neck radiotherapy [53]. In this regard, the study of Weber et al. [48] showed a low incidence rate of serious toxicity since they were able to deliver to the lachrymal apparatus a dose below the generally accepted threshold value of 30 Gy [53]. Furthermore, their good results may be related to the use of a twice-a-day fractionation schedule. Monroe et al. [58] studying 186 patients with head and neck malignancies found that a twice-a-day hyperfractionation schedule with 


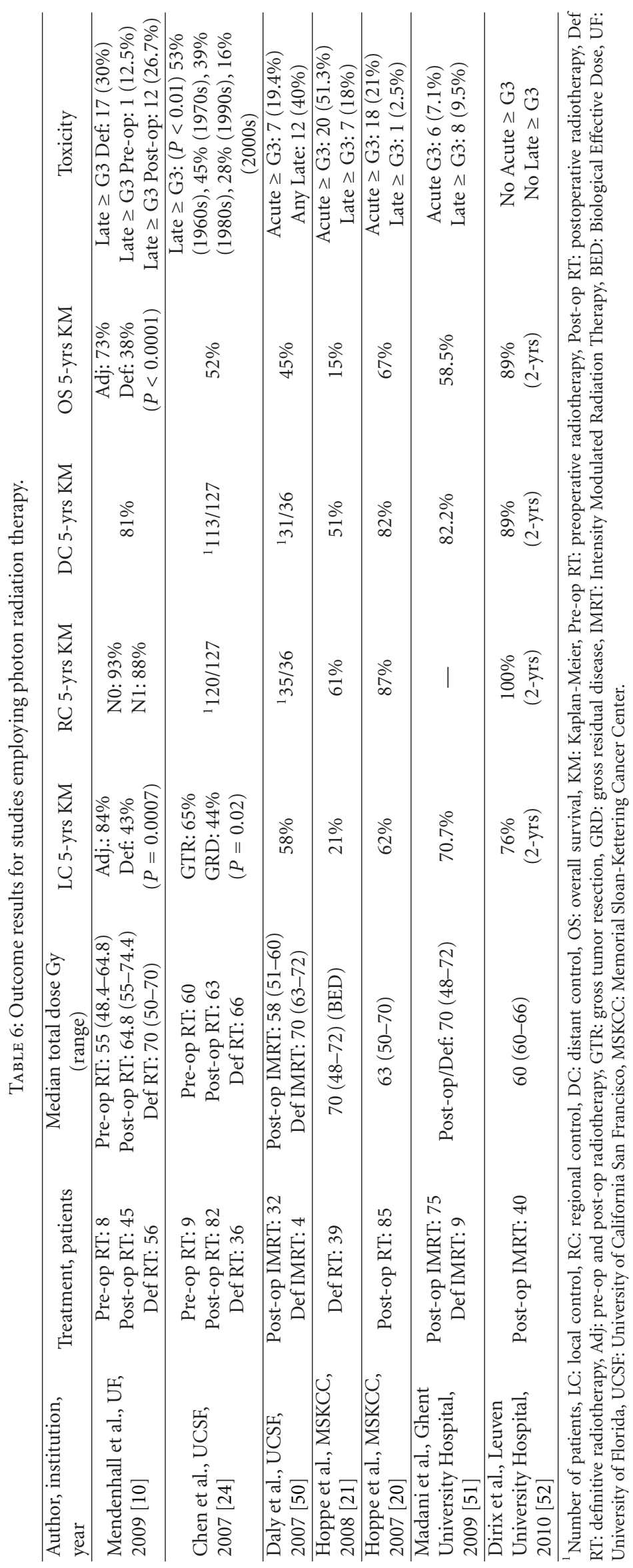


single doses between 1.1 and $1.2 \mathrm{~Gy}$, separated at least by $4 \mathrm{~h}-6 \mathrm{~h}$, was significantly associated with lower incidence of retinopathy. The same group (Bhandare et al. [59]) observed that also optic neuropathy may be reduced with the same schema. This is in accordance also with the report of Malyapa et al. [39] that described just one case of mild retinopathy for a group of patients treated with hyperfractionated proton therapy. As regards to hypofractionation, Parsons et al. [60] showed that the use of larger fraction size is associated with retinal toxicity. In the study of Demizu et al. [46], single fraction was 3.6 Gy (RBE) for carbon ions and 2.5 Gy (RBE) for protons and they did not raise particular concern about the utilization of high-dose per fraction.

Other risk factors found by the specific studies were diabetes mellitus that has already been associated with toxicity by other authors $[59,61]$ and age where data from published experience are not definitive $[22,58,59]$. The study of Weber et al. [48] has the apparently paradox finding that younger age is linked with higher toxicity. This may be explained with the longer follow-up period elapsed for this group of patients. Data on the use of chemotherapy are not definitive: it is positively related to toxicity at univariate analysis in the study of Hasegawa et al. [47] but not for Weber et al. [48], Bhandare et al. [59], and Takeda et al. [56].

Brain late side effects have always been among the most dreaded consequences of radiation therapy. Significant neurologic alterations have been described in association with photon and particle radiotherapy for paranasal and nasal cavity malignancies [23, 62]. The study of Miyawaki et al. [49] has a good toxicity profile with just one patient out of 28 experiencing G3 brain toxicity, that is, epilepsy requiring medical treatment. Factors related to toxicity were dose $\geq 80 \mathrm{~Gy}(\mathrm{RBE})_{3}$ and volumes of cerebral lobe receiving more than 83,90 , and $100 \mathrm{~Gy}(\mathrm{RBE})_{3}$. Maximum dose and volume receiving a given dose are recognized risk factors for brain toxicity. From the review of published data, Lawrence et al. [63] could conclude that the incidence and severity of brain side effects is dose and volume dependent. Brain necrosis incidence of $5 \%$ occurs for $\operatorname{BED}_{(\alpha / \beta=3)}=120 \mathrm{~Gy}$, if standard fractionation regimes are employed. Experiences with single fraction radiosurgery clearly demonstrate a correlation between target size and side effects. The study of Debus et al. [64] about 367 patients receiving photon/proton radiation therapy for skull base chordoma and chondrosarcoma found a 10 -year brainstem toxicity-free survival of $88 \%$; risk factors at multivariate analysis were diabetes, number of surgical procedures, and volume of brainstem receiving $60 \mathrm{~Gy}$ (RBE) $(P<0.001)$. Schlampp et al. [65] observed 10 temporal lobe reactions at MRI out of 59 patients treated with carbon ions for chordoma and chondrosarcoma of the skull base. Most important predictors of toxicity were age and maximum dose applied to at least $1 \mathrm{~cm}^{3}$ of the temporal lobe. Carbon ions were found by Miyawaki et al. [49] to be significantly more frequently associated than protons with brain toxicity. According to the author, a reason could be found in the different fractionation schedules employed: single-fraction carbon ion dose of 3.6 Gy (RBE) would be more toxic than a proton one of $2.5 \mathrm{~Gy}$ (RBE). Some studies in the literature support this hypothesis as, for example, the report of Lee et al. [66] about 1008 patients treated for nasopharyngeal carcinoma: significantly higher incidence of temporal lobe necrosis was associated with single fraction size of 4.2 Gy. Lawrence et al. [63] in their review could not make any definitive conclusion about incidence and severity of toxicity when fractionated radiation therapy with single doses $>2.5$ Gy is used. Also in this case, the effect of the higher $\mathrm{RBE}$ of carbon ion cannot be ruled out definitely.

\section{Conclusions}

Particle radiation therapy is a promising tool for the treatment of paranasal and nasal cavity malignancies. Considering that it is in its early phases of development, it has shown to be feasible and well tolerated. Results regarding local control are encouraging and late toxicity is acceptable. Further research is needed to establish its exact role and its best combination with surgery and chemotherapy.

\section{References}

[1] C. S. Muir and J. Nectoux, "Descriptive epidemiology of malignant neoplasms of nose, nasal cavities, middle ear and accessory sinuses," Clinical Otolaryngology and Allied Sciences, vol. 5, no. 3, pp. 195-211, 1980.

[2] G. C. Roush, "Epidemiology of cancer of the nose and paranasal sinuses: current concepts," Head and Neck Surgery, vol. 2, no. 1, pp. 3-11, 1979.

[3] P. Dulguerov, M. S. Jacobsen, A. S. Allal et al., "Nasal and paranasal sinus carcinoma: are we making progress? A series of 220 patients and a systematic review," Cancer, vol. 92, pp. 30123029, 2001.

[4] C. Grau, M. H. Jakobsen, G. Harbo et al., "Sino-nasal cancer in Denmark 1982-1991: a nationwide survey," Acta Oncologica, vol. 40, no. 1, pp. 19-23, 2001.

[5] A. E. Chang, L. H. Karnell, and H. R. Menck, "The National Cancer Data Base report on cutaneous and noncutaneous melanoma," Cancer, vol. 83, pp. 1664-1678, 1998.

[6] G. P. Siegal, W. R. Oliver, W. R. Reinus et al., "Primary Ewing's sarcoma involving the bones of the head and neck," Cancer, vol. 60, no. 11, pp. 2829-2840, 1987.

[7] B. O. Potter and E. M. Sturgis, "Sarcomas of the head and neck," Surgical Oncology Clinics of North America, vol. 12, no. 2, pp. 379-417, 2003.

[8] D. I. Rosenthal, J. L. Barker, A. K. El-Naggar et al., "Sinonasal malignancies with neuroendocrine differentiation: patterns of failure according to histologic phenotype," Cancer, vol. 101, no. 11, pp. 2567-2573, 2004.

[9] P. Dirix, S. Nuyts, B. Vanstraelen et al., "Post-operative intensity-modulated radiotherapy for malignancies of the nasal cavity and paranasal sinuses," Radiotherapy and Oncology, vol. 85, no. 3, pp. 385-391, 2007.

[10] W. M. Mendenhall, R. J. Amdur, C. G. Morris et al., "Carcinoma of the nasal cavity and paranasal sinuses," Laryngoscope, vol. 119, no. 5, pp. 899-906, 2009.

[11] I. Ganly, S. G. Patel, B. Singh et al., "Craniofacial resection for malignant tumors involving the skull base in the elderly," Cancer, vol. 117, no. 3, pp. 563-571, 2011.

[12] G. Cantu, C. L. Solero, R. Miceli et al., "Anterior craniofacial resection for malignant paranasal tumors: a monoinstitutional experience of 366 cases," Head and Neck, vol. 34, no. 1, pp. 7887, 2011. 
[13] S. G. Patel, B. Singh, A. Polluri et al., "Craniofacial surgery for malignant skull base tumors: report of an international collaborative study," Cancer, vol. 98, no. 6, pp. 1179-1187, 2003.

[14] V. Lund, D. J. Howard, and W. I. Wei, "Endoscopic resection of malignant tumors of the nose and sinuses," American Journal of Rhinology, vol. 21, no. 1, pp. 89-94, 2007.

[15] E. Hanna, F. DeMonte, S. Ibrahim, D. Roberts, N. Levine, and M. Kupferman, "Endoscopic resection of sinonasal cancers with and without craniotomy: oncologic results," Archives of Otolaryngology, vol. 135, no. 12, pp. 1219-1224, 2009.

[16] P. Nicolai, A. B. Villaret, M. Bottazzoli et al., "Ethmoid adenocarcinoma-from craniofacial to endoscopic resections: a single-institution experience over 25 years," Otolaryngol Head Neck Surgery, vol. 145, no. 2, pp. 330-337, 2011.

[17] L. Licitra, L. D. Locati, R. Cavina et al., "Primary chemotherapy followed by anterior craniofacial resection and radiotherapy for paranasal cancer," Annals of Oncology, vol. 14, no. 3, pp. 367-372, 2003.

[18] E. Y. Hanna, A. D. Cardenas, F. DeMonte et al., "Induction chemotherapy for advanced squamous cell carcinoma of the paranasal sinuses," Archives of Otolaryngology, vol. 137, no. 1, pp. 78-81, 2011.

[19] M. Airoldi, M. Garzaro, G. Valente et al., "Clinical and biological prognostic factors in 179 cases with sinonasal carcinoma treated in the italian piedmont region," Oncology, vol. 76, no. 4, pp. 262-269, 2009.

[20] B. S. Hoppe, L. D. Stegman, M. J. Zelefsky et al., "Treatment of nasal cavity and paranasal sinus cancer with modern radiotherapy techniques in the postoperative setting-the MSKCC experience," International Journal of Radiation Oncology Biology Physics, vol. 67, no. 3, pp. 691-702, 2007.

[21] B. S. Hoppe, C. J. Nelson, D. R. Gomez et al., "Unresectable carcinoma of the paranasal sinuses: outcomes and toxicities," International Journal of Radiation Oncology Biology Physics, vol. 72, no. 3, pp. 763-769, 2008.

[22] J. T. Parsons, F. J. Bova, C. R. Fitzgerald, W. M. Mendenhall, and R. R. Million, "Radiation optic neuropathy after megavoltage external-beam irradiation: analysis of time-dose factors," International Journal of Radiation Oncology Biology Physics, vol. 30, no. 4, pp. 755-763, 1994.

[23] C. A. Meyers, F. Geara, P. F. Wong, and W. H. Morrison, "Neurocognitive effects of therapeutic irradiation for base of skull tumors," International Journal of Radiation Oncology Biology Physics, vol. 46, no. 1, pp. 51-55, 2000.

[24] A. M. Chen, M. E. Daly, M. K. Bucci et al., "Carcinomas of the paranasal sinuses and nasal cavity treated with radiotherapy at a single institution over five decades: are we making improvement?" International Journal of Radiation Oncology Biology Physics, vol. 69, no. 1, pp. 141-147, 2007.

[25] T. A. van de Water, H. P. Bijl, C. Schilstra, M. PijlsJohannesma, and J. A. Langendijk, "The potential benefit of radiotherapy with protons in head and neck cancer with respect to normal tissue sparing: a systematic review of literature," Oncologist, vol. 16, no. 3, pp. 366-377, 2011.

[26] H. Paganetti, A. Niemierko, M. Ancukiewicz et al., "Relative biological effectiveness (RBE) values for proton beam therapy," International Journal of Radiation Oncology Biology Physics, vol. 53, no. 2, pp. 407-421, 2002.

[27] K. Ando, S. Koike, K. Kawachi et al., "Relative biological effectiveness of the therapeutic proton beams at NIRS and Tsukuba University," Nippon Igaku Hoshasen Gakkai zasshi, vol. 45, no. 3, pp. 531-535, 1985.
[28] The International Commission on Radiation Units and Measurements, "Prescribing, recording, and reporting proton beam therapy," Journal of the ICRU, vol. 7, no. 2, report 78, 2007.

[29] H. Tsujii, T. Kamada, M. Baba et al., "Clinical advantages of carbon-ion radiotherapy," New Journal of Physics, vol. 10, Article ID 075009, 2008.

[30] L. L. Gunderson and J. E. Tepper, Clinical Radiation Oncology, Elsevier Saunders, Philadelphia, Pa, USA, 3rd edition, 2011.

[31] J. E. Mizoe, H. Tsujii, T. Kamada et al., "Dose escalation study of carbon ion radiotherapy for locally advanced headand-neck cancer," International Journal of Radiation Oncology Biology Physics, vol. 60, no. 2, pp. 358-364, 2004.

[32] H. Tsujii, S. Morita, T. Miyamoto et al., "Preliminary results of phase I/II carbon-ion therapy at the National Institute of Radiological Sciences," Journal of Brachytherapy International, vol. 13, no. 1, pp. 1-8, 1997.

[33] J. Bourhis, J. Overgaard, H. Audry et al., "Hyperfractionated or accelerated radiotherapy in head and neck cancer: a metaanalysis," The Lancet, vol. 368, no. 9538, pp. 843-854, 2006.

[34] H. Yamazaki, K. Nishiyama, E. Tanaka, M. Koizumi, and M. Chatani, "Radiotherapy for early glottic carcinoma (T1N0M0): results of prospective randomized study of radiation fraction size and overall treatment time," International Journal of Radiation Oncology Biology Physics, vol. 64, no. 1, pp. 77-82, 2006.

[35] D. Schulz-Ertner and H. Tsujii, "Particle radiation therapy using proton and heavier ion beams," Journal of Clinical Oncology, vol. 25, no. 8, pp. 953-964, 2007.

[36] R. Imai, T. Kamada, S. Sugahara et al., "Carbon ion radiotherapy for sacral chordomas," British Journal of Radiology, vol. 84, pp. S48-S54, 2011.

[37] J. F. Fowler, "The linear-quadratic formula and progress in fractionated radiotherapy," British Journal of Radiology, vol. 62, no. 740, pp. 679-694, 1989.

[38] Systematic Reviews, CRD's Guidance for Undertaking Reviews in Health Care, Centre for Reviews and Dissemination, University of York, York, UK, 2009.

[39] R. S. Malyapa, D. Yeung, C. McKenzie et al., "Proton therapy of nasal cavity and paranasal sinuses: the UFPTI Experience," International Journal of Radiation Oncology Biology Physics, vol. 78, no. 3, p. S450, 2010.

[40] J. R. Castro, D. E. Linstadt, J. P. Bahary et al., "Experience in charged particle irradiation of tumors of the skull base: 19771992," International Journal of Radiation Oncology Biology Physics, vol. 29, no. 4, pp. 647-655, 1994.

[41] T. Kanai, M. Endo, S. Minohara et al., "Biophysical characteristics of HIMAC clinical irradiation system for heavy-ion radiation therapy," International Journal of Radiation Oncology Biology Physics, vol. 44, no. 1, pp. 201-210, 1999.

[42] K. Tokuuye, Y. Akine, K. Kagei et al., "Proton Therapy for Head and Neck Malignancies at Tsukuba," Strahlentherapie und Onkologie, vol. 180, no. 2, pp. 96-101, 2004.

[43] V. A. Resto, A. W. Chan, D. G. Deschler, and D. T. Lin, "Extent of surgery in the management of locally advanced sinonasal malignancies," Head and Neck, vol. 30, no. 2, pp. 222-229, 2008.

[44] S. Zenda, R. Kohno, M. Kawashima et al., "Proton beam therapy for unresectable malignancies of the nasal cavity and paranasal sinuses," International Journal of Radiation Oncology Biology Physics, vol. 81, no. 5, pp. 1473-1478, 2011.

[45] A. D. Jensen, A. V. Nikoghosyan, S. Ecker, M. Ellerbrock, J. Debus, and M. W. Münter, "Carbon ion therapy for advanced sinonasal malignancies: feasibility and acute toxicity," Radiation Oncology, vol. 6, no. 1, article no. 30, 2011. 
[46] Y. Demizu, M. Murakami, D. Miyawaki et al., "Analysis of vision loss caused by radiation-induced optic neuropathy after particle therapy for head-and-neck and skull-base tumors adjacent to optic nerves," International Journal of Radiation Oncology Biology Physics, vol. 75, no. 5, pp. 1487-1492, 2009.

[47] A. Hasegawa, J. E. Mizoe, A. Mizota, and H. Tsujii, "Outcomes of visual acuity in carbon ion radiotherapy: analysis of dosevolume histograms and prognostic factors," International Journal of Radiation Oncology Biology Physics, vol. 64, no. 2, pp. 396-401, 2006.

[48] D. C. Weber, A. W. Chan, S. Lessell et al., "Visual outcome of accelerated fractionated radiation for advanced sinonasal malignancies employing photons/protons," Radiotherapy and Oncology, vol. 81, no. 3, pp. 243-249, 2006.

[49] D. Miyawaki, M. Murakami, Y. Demizu et al., "Brain injury after proton therapy or carbon ion therapy for head-andneck cancer and skull base tumors," International Journal of Radiation Oncology Biology Physics, vol. 75, no. 2, pp. 378-384, 2009.

[50] M. E. Daly, A. M. Chen, M. K. Bucci et al., "Intensity-modulated radiation therapy for malignancies of the nasal cavity and paranasal sinuses," International Journal of Radiation Oncology Biology Physics, vol. 67, no. 1, pp. 151-157, 2007.

[51] I. Madani, K. Bonte, L. Vakaet, T. Boterberg, and W. De Neve, "Intensity-modulated radiotherapy for sinonasal tumors: Ghent University Hospital update," International Journal of Radiation Oncology Biology Physics, vol. 73, no. 2, pp. 424-432, 2009.

[52] P. Dirix, B. Vanstraelen, M. Jorissen, V. Vander Poorten, and S. Nuyts, "Intensity-modulated radiotherapy for sinonasal cancer: improved outcome compared to conventional radiotherapy," International Journal of Radiation Oncology Biology Physics, vol. 78, no. 4, pp. 998-1004, 2010.

[53] J. T. Parsons, F. J. Bova, C. R. Fitzgerald, W. M. Mendenhall, and R. R. Million, "Severe dry-eye syndrome following external beam irradiation," International Journal of Radiation Oncology Biology Physics, vol. 30, no. 4, pp. 775-780, 1994.

[54] G. l. Jiang, S. L. Tucker, R. Guttenberger et al., "Radiation-induced injury to the visual pathway," Radiotherapy and Oncology, vol. 30, pp. 17-25, 1994.

[55] J. L. Habrand, M. Austin-Seymour, S. Birnbaum et al., "Neurovisual outcome following proton radiation therapy," International Journal of Radiation Oncology Biology Physics, vol. 16, no. 6, pp. 1601-1606, 1989.

[56] A. Takeda, N. Shigematsu, S. Suzuki et al., "Late retinal complications of radiation therapy for nasal and paranasal malignancies: relationship between irradiated-dose area and severity," International Journal of Radiation Oncology Biology Physics, vol. 44, no. 3, pp. 599-605, 1999.

[57] M. M. Urie, B. Fullerton, H. Tatsuzaki et al., "A dose response analysis of injury to cranial nerves and/or nuclei following proton beam radiation therapy," International Journal of Radiation Oncology Biology Physics, vol. 23, no. 1, pp. 27-39, 1992.

[58] A. T. Monroe, N. Bhandare, C. G. Morris, and W. M. Mendenhall, "Preventing radiation retinopathy with hyperfractionation," International Journal of Radiation Oncology Biology Physics, vol. 61, no. 3, pp. 856-864, 2005.

[59] N. Bhandare, A. T. Monroe, C. G. Morris, M. T. Bhatti, and W. M. Mendenhall, "Does altered fractionation influence the risk of radiation-induced optic neuropathy?" International Journal of Radiation Oncology Biology Physics, vol. 62, no. 4, pp. 10701077, 2005.
[60] J. T. Parsons, F. J. Bova, C. R. Fitzgerald, W. M. Mendenhall, and R. R. Million, "Radiation retinopathy after externalbeam irradiation: analysis of time- dose factors," International Journal of Radiation Oncology Biology Physics, vol. 30, no. 4, pp. 765-773, 1994.

[61] E. S. Gragoudas, W. Li, A. M. Lane, J. Munzenrider, and K. M. Egan, "Risk factors for radiation maculopathy and papillopathy after intraocular irradiation," Ophthalmology, vol. 106, no. 8, pp. 1571-1578, 1999.

[62] R. Kishimoto, J. E. Mizoe, S. Komatsu, S. Kandatsu, T. Obata, and H. Tsujii, "MR imaging of brain injury induced by carbon ion radiotherapy for head and neck tumors," Magnetic Resonance in Medical Sciences, vol. 4, no. 4, pp. 159-164, 2005.

[63] Y. R. Lawrence, X. A. Li, I. el Naqa et al., "Radiation dosevolume effects in the brain," International Journal of Radiation Oncology Biology Physics, vol. 76, no. 3, pp. S20-S27, 2010.

[64] J. Debus, E. B. Hug, N. J. Liebsch et al., "Brainstem tolerance to conformal radiotherapy of skull base tumors," International Journal of Radiation Oncology Biology Physics, vol. 39, no. 5, pp. 967-975, 1997.

[65] I. Schlampp, C. P. Karger, O. Jäkel et al., “Temporal lobe reactions after radiotherapy with carbon ions: incidence and estimation of the relative biological effectiveness by the local effect model," International Journal of Radiation Oncology Biology Physics, vol. 80, no. 3, pp. 815-823, 2011.

[66] A. W. M. Lee, W. Foo, R. Chappell et al., "Effect of time, dose, and fractionation on temporal lobe necrosis following radiotherapy for nasopharyngeal carcinoma," International Journal of Radiation Oncology Biology Physics, vol. 40, no. 1, pp. 35-42, 1998. 


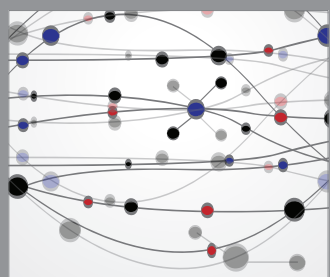

The Scientific World Journal
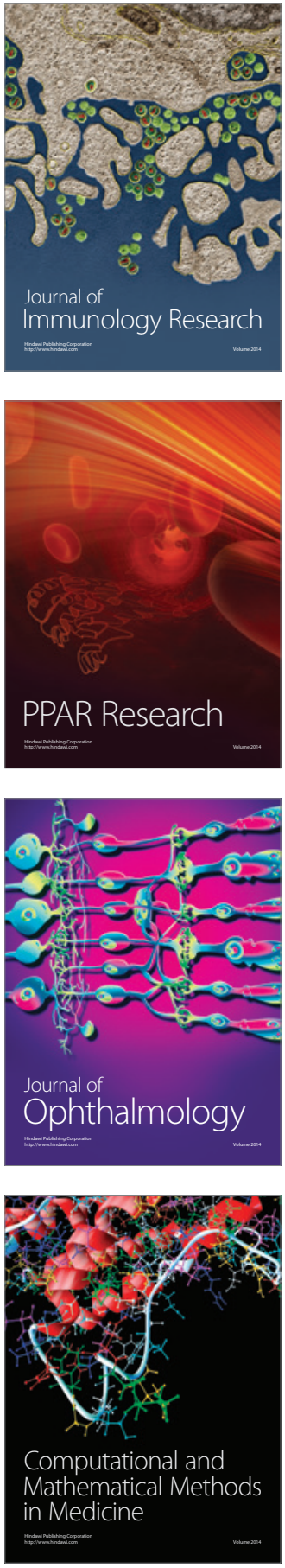

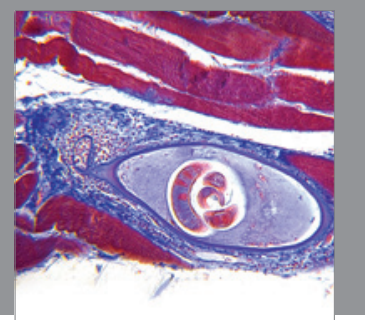

Gastroenterology

Research and Practice
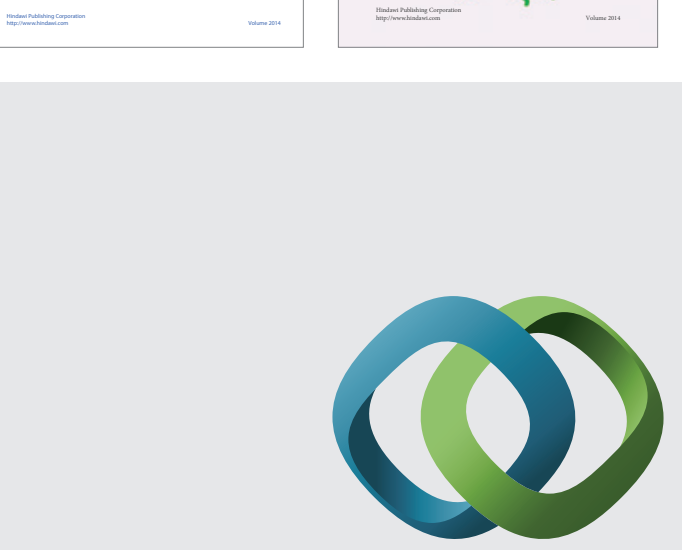

\section{Hindawi}

Submit your manuscripts at

http://www.hindawi.com
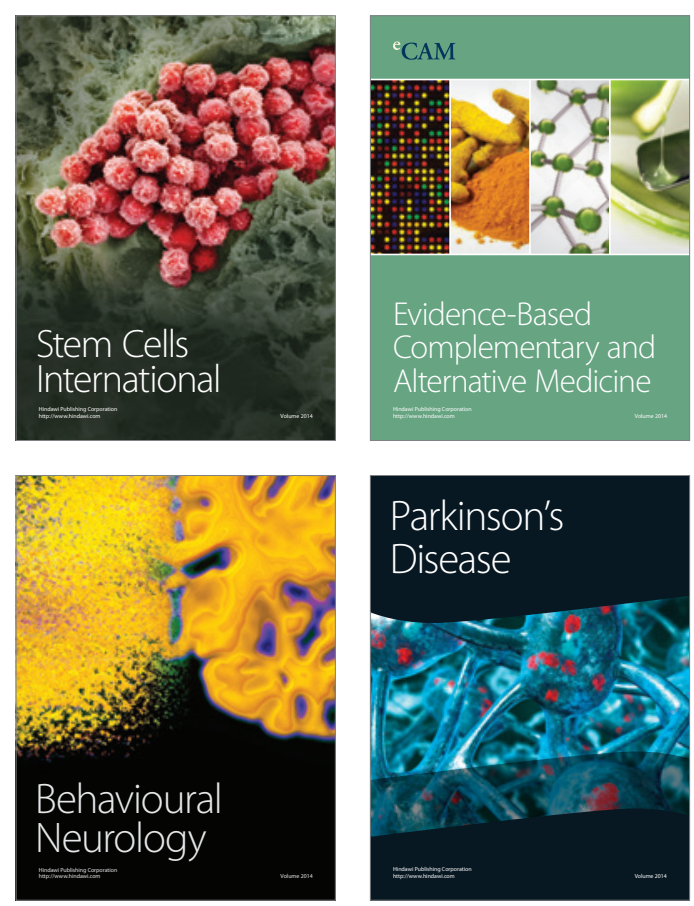

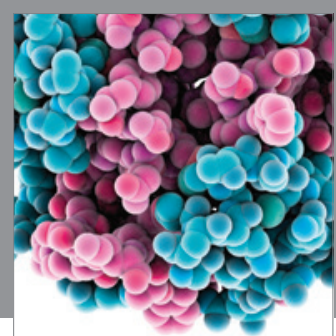

Journal of
Diabetes Research

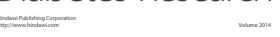

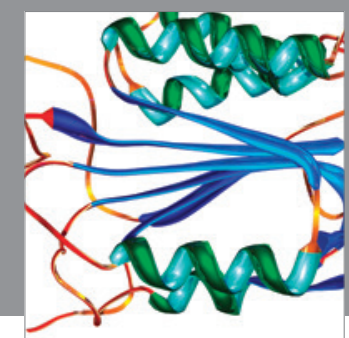

Disease Markers
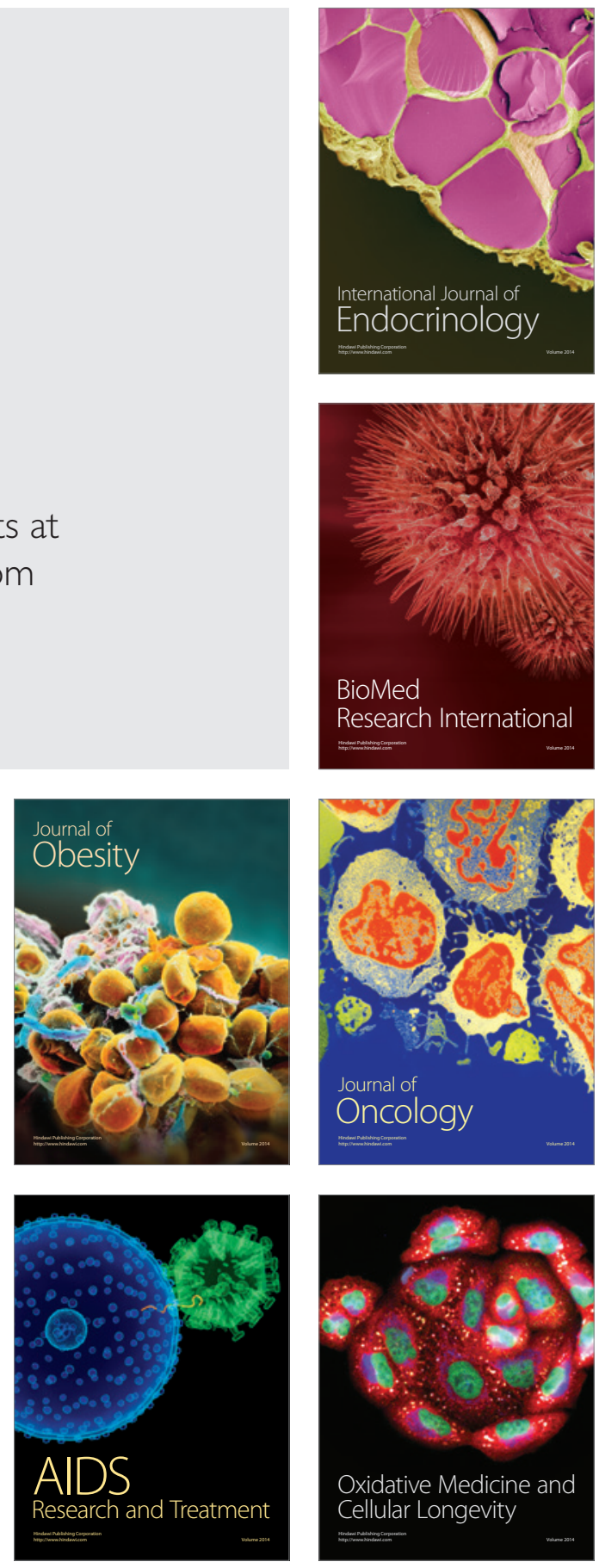